Check for updates

Cite this: RSC Adv., 2019, 9, 29813

Received 27th July 2019

Accepted 12th September 2019

DOI: 10.1039/c9ra05833h

rsc.li/rsc-advances

\section{Relationship between dynamic fatigue crack propagation properties and viscoelasticity of natural rubber/silicone rubber composites $\uparrow$}

\author{
Qingyuan Han, ${ }^{a}$ Liqun Zhang (iD ab and Youping Wu (iD *ab
}

In this paper, dynamic fatigue crack propagation properties of natural rubber/silicone rubber (NR/VMQ) composites are studied under constant tearing energy $(G)$ input. Through dynamic fatigue crack growth testing, it is found that with the increase of VMQ fraction, NR/VMQ exhibits a lower crack growth rate $(\mathrm{d} c / \mathrm{d} N)$. The viscoelastic parameters have been recorded in real-time during crack propagation, including the storage modulus $E^{\prime}$, loss factor $\tan \delta$, and loss compliance modulus $\mathrm{J}^{\prime \prime}$, and their relationships with crack propagation behaviour have been established. The improved crack propagation resistance is attributed to the reduced $J^{\prime \prime}$, resulting from the synergistic effect of increased $E^{\prime}$ and decreased $\tan \delta$, and thus more energy dissipation occurred in the linear viscoelastic region in front of the crack tip, which consumed part of the energy for crack growth. Finally, good correlation between $\mathrm{dc} / \mathrm{d} N$ and $\mathrm{J}^{\prime \prime}$ could be successfully established.

\section{Introduction}

The fatigue phenomenon widely exists in rubber products, such as tires, seals, dampers and conveyor belts, which are usually exposed to dynamic stress. Therefore, exploring the fatigue damage mechanism of rubber composites has great significance in improving the service life of their products.

According to the rubber fracture mechanics theory established by Rivlin and Thomas, ${ }^{1}$ when a pre-notched rubber strip is torn, the strain energy consumed to produce a unit area of new crack surface is called tearing energy $(G)$ :

$$
G=-\frac{\partial U}{\partial A}
$$

where $U$ refers to the elastic energy stored in rubber, and $A$ is the cross-sectional area of the crack.

With the increase of $G$, crack growth rate $(\mathrm{d} c / \mathrm{d} N)$ would increase in four different manners. ${ }^{2}$ When $G$ exceeds critical tearing energy $G_{\mathrm{c}}$, in the power-law region, $\mathrm{d} c / \mathrm{d} N-G$ exhibits an exponential relationship:

$$
\frac{\mathrm{d} c}{\mathrm{~d} N}=A G^{\alpha}
$$

\footnotetext{
${ }^{a}$ State Key Laboratory of Organic-Inorganic Composites, Beijing University of Chemical Technology, Beijing 100029, China. E-mail: wuyp@mail.buct.edu.cn; Fax: +86-1064456158; Tel: +86-10-64442621

${ }^{b}$ Beijing Engineering Research Centre of Advanced Elastomers, Beijing University of Chemical Technology, Beijing 100029, China

$\dagger$ Electronic supplementary information (ESI) available. See DOI: 10.1039/c9ra05833h
}

where $A$ is the pre-exponential factor, and $\alpha$ reflects the sensitivity of $\mathrm{d} c / \mathrm{d} N$ to the change of $G .^{3}$

Furthermore, Persson and Brener have pointed out that the energy dissipation around the crack $G(v)$ consists of two parts: ${ }^{4}$

$$
\begin{aligned}
G(v) & =G_{0}[1+f(v, T)] \\
& =G_{0}+G_{0} f(v, T)=G_{0}+G_{0} f\left(\alpha_{\mathrm{T}} v\right)
\end{aligned}
$$

As shown in Fig. 1, $G_{0}$ occurs in the innermost area of the crack tip, and it is a highly non-linear process, which includes forming of cavities, breaking of chemical bonds, pulling out of molecular chains and stringing; $G_{0} f(v, T)$ is the bulk dissipation of linear viscoelastic region in front of the crack tip, which makes the major contribution to $G(v)$, where $f(v, T)$ is a function of crack growth rate $v$ and temperature $T$. And according to the time-temperature equivalence principle, $T$ could be replaced by the Williams-Landel-Ferry (WLF) coefficient $\alpha_{\mathrm{T}}{ }^{5}$ so that $G(v)$ could be presented as the function of time (frequency) without temperature:

$$
\begin{aligned}
G(v) & =G_{0}+G_{0} f\left(\alpha_{\mathrm{T}} v\right) \\
& =G_{0}\left[1-\frac{2}{\pi} E_{0} \int_{0}^{2 \pi v / \mathrm{a}} \mathrm{d} \omega \frac{F(\omega)}{\omega} \operatorname{Im} \frac{1}{E^{*}(\omega)}\right]^{-1}
\end{aligned}
$$

where $E_{0}$ is the storage modulus of the bulk dissipated region, $\omega$ stands for perturbing frequency, which is defined as $v / r(r$ is the distance from the crack tip). $F(\omega)$ is a function of $\omega, v$ and $a$ (diameter of the crack tip), which is defined as $[1-(\omega a)$ $\left.2 \pi v)^{2}\right]^{1 / 2} \cdot E^{*}(\omega)$ is called complex modulus, and the imaginary part of $\left[1 / E^{*}(\omega)\right]$ is: ${ }^{4,5}$ 


$$
\begin{aligned}
& \operatorname{Im} \frac{1}{E^{*}(\omega)}=-\frac{E^{\prime \prime}}{\left|E^{*}\right|} \\
& \quad=-J^{\prime \prime}=-\frac{E^{\prime \prime}}{E^{\prime 2}+E^{\prime \prime 2}}=-\frac{E^{\prime} \tan \delta}{E^{\prime 2}+E^{\prime 2} \tan ^{2} \delta}=-\frac{\tan \delta}{E^{\prime}+E^{\prime} \tan ^{2} \delta}
\end{aligned}
$$

$\left[E^{\prime \prime} /\left|E^{*}\right|\right]$ is loss compliance modulus $J^{\prime \prime}$, which is also the function of storage modulus $E^{\prime}$ and loss factor tan $\delta$. Therefore, eqn (4) could also be written as the form of $G(v)-J^{\prime \prime}$ as shown in eqn $(6) .{ }^{6,7}$

$$
G(v)=G_{0}\left[1+\frac{2}{\pi} E_{0} \int_{0}^{2 \pi v / \mathrm{a}} \mathrm{d} \omega \frac{F(\omega)}{\omega} J^{\prime \prime}\right]^{-1}
$$

Because of the characteristic of strain induced crystallization (SIC), natural rubber (NR) exhibits outstanding mechanical strength and fatigue crack propagation resistance, but its antiageing properties is poor. As for the highly saturated and inorganic backbone structure $(-\mathrm{Si}-\mathrm{O}-)$ of silicone rubber (VMQ), it possesses excellent high-temperature and ageing resistance. So in this study, NR/VMQ composites $^{\mathbf{8}, 9}$ were prepared to improve anti-ageing and anti-fatigue properties of tire materials at the same time..$^{\mathbf{1 0 - 1 2}}$

Constant strain/stress loading conditions are generally used in fatigue testing, ${ }^{13}$ but different modulus of rubber would lead to different $G$ input, further to influence their fatigue properties. Therefore, here we have kept $G$ input constant, and storage modulus $E^{\prime}$, loss factor $\tan \delta$ and loss compliance modulus $J^{\prime \prime}$ were recorded real-time as function of fatigue cycles during crack propagation testing. The purpose of our study is to establish a connection between fatigue crack propagation properties and bulk viscoelastic properties of NR/VMQ composites. ${ }^{\mathbf{1 4 , 1 5}}$

\section{Experimental}

\section{Materials}

NR smoke sheet $1^{\#}$ was purchased from Indonesia. VMQ 110-9 $\left(M_{\mathrm{n}}=4.5 \times 10^{5}\right.$, vinyl content $\left.=5 \%\right)$ was provided by Hesheng Silicon Industry Co., Ltd. (Zhejiang, China). Precipitated silica (Ultrasil VN3) was purchased from Evonik Degussa Co., Ltd. (Qingdao, China). Silane coupling agent TESPT (bis-[3(triethoxysilyl)-propyl]-tetrasulfide) was provided by Shuguang

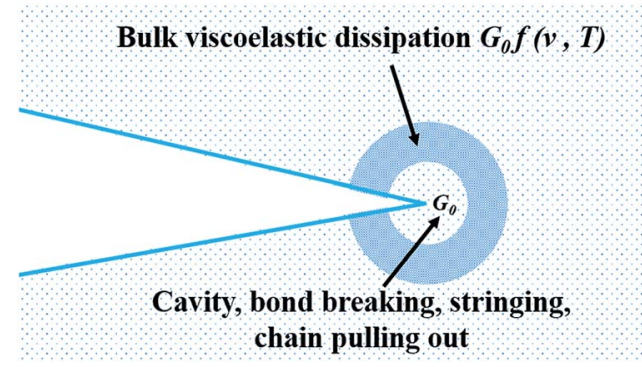

Fig. 1 Contribution of energy dissipation in the crack tip. chemical Co., Ltd. (Nanjing, China). Silane coupling agent VTES $\left(\mathrm{CH}_{2}=\mathrm{CHSi}\left(\mathrm{OC}_{2} \mathrm{H}_{5}\right)_{3}\right)$ was purchased from Chenguang Chemical Industry Co., Ltd. (Shandong, China). Curing agent DBPMH (2,5-dimethyl-2,5-di(tert-butylperoxy)-hexane) was provided by AkzoNobel Co., Ltd (Jiangsu, China). Other ingredients are all commercially available products.

\section{Sample preparation}

In order to overcome the mixing difficulties caused by the large viscosity difference between NR and VMQ, VMQ/silica masterbatch was firstly prepared by a two-roll mill $(\mathrm{X}(\mathrm{S}) \mathrm{K}$ 160, Shanghai rubber machinery Co., Ltd., China) with feeding ratio of VMQ : silica: VTES : hydroxyl terminated polysiloxane $=100: 35: 3: 1 .^{16}$ Then a two-stage procedure was adopted for the preparation of NR/VMQ compounds according to formula shown in Table 1. The first stage was conducted in a Haake torque rheometer (RM-200C, Hapro electric technology Co., Ltd, Harbin, China) with rotor speed of $60 \mathrm{rpm}$ and filling fraction of 0.7 . When temperature of the mixing chamber rose to $100^{\circ} \mathrm{C}$, rubber, silica, silane coupling agent TESPT, antioxidants TMQ and MB were mixed in sequence. When temperature reached $145{ }^{\circ} \mathrm{C}$, maintained 5 min for complete silanization, then dumped. The second stage was conducted on two-roll mill, and curing agent DBPMH was mixed into the first- stage compounds.

Rotorless moving die rheometer (MR-C3, RADE instrument Co., Ltd., Beijing, China) was applied to determine optimum vulcanization time $\left(t_{90}\right)$. Then a platen press vulcanizer (LBD350 $\times$ 350, Dongfang machinery Co., Ltd., Huzhou, China) was conducted to prepare vulcanized specimens under pressure of $15 \mathrm{MPa}$ at $170{ }^{\circ} \mathrm{C}$ for $t_{90}$.

\section{Physical mechanical properties testing}

An electronic tensile machine (SANS Test Machine Corporation, Shenzhen, China) was conducted to test tensile properties, which according to standard ISO 37: 2011, with cross-head speed of $500 \mathrm{~mm} \mathrm{~min}^{-1}$.

\section{Rubber processing analysis (RPA)}

Strain amplitude dependence of viscoelastic parameters in NR/

\begin{tabular}{|c|c|c|c|c|}
\hline NR/VMQ & $100 / 0$ & $90 / 10$ & $80 / 20$ & $70 / 30$ \\
\hline NR & 100 & 90 & 80 & 70 \\
\hline VMQ & 0 & 10 & 20 & 30 \\
\hline Silica & 50 & 50 & 50 & 50 \\
\hline Silane coupling agent & 4 & 4 & 4 & 4 \\
\hline Curing agent DBPMH & 2 & 2 & 2 & 2 \\
\hline Antioxidant $\mathrm{TMQ}^{b}$ & 1 & 1 & 1 & 1 \\
\hline Antioxidant $\mathrm{MB}^{c}$ & 1 & 1 & 1 & 1 \\
\hline Hydroxyl terminated polysiloxane & 0 & 0.1 & 0.2 & 0.3 \\
\hline Total & 158 & 158.1 & 158.2 & 158.3 \\
\hline
\end{tabular}
VMQ compounds were measured by rubber processing analyzer

Table 1 Formula of NR/VMQ compounds $(\mathrm{phr})^{a}$ 
RPA (RPA 2000, Alpha technology Co., Ltd., America) with strain range of $0.28-400 \%$ and frequency of $1 \mathrm{~Hz}$ at $100{ }^{\circ} \mathrm{C}$. After the first strain-sweeping, all compounds were vulcanized at $170{ }^{\circ} \mathrm{C}$ for $t_{90}$. Then the vulcanizates were conducted by strainsweeping with range of $0.28-40 \%$ and frequency of $10 \mathrm{~Hz}$ at $60{ }^{\circ} \mathrm{C}$.

\section{Transmission electron microscopy (TEM)}

Phase morphology of NR/VMQ masterbatch and silica dispersion morphology of its filled composites were investigated by TEM (H-9500, Hitachi Co., Ltd., Japan) with accelerating voltage of $200 \mathrm{kV}$. Samples for TEM were cut by an ultra-microtome (EM FC7, Leica Co., Ltd., Germany) under cooling of liquid nitrogen at $-100{ }^{\circ} \mathrm{C}$.

\section{Atomic force microscopy (AFM)}

Phase morphology of NR/VMQ masterbatch was also studied by AFM (Nanoscope IV Controller, Bruker Co., Ltd., Germany) in Peak Force Quantitative Nano-Mechanical mode. Samples for AFM were cut and polished by the ultra-microtome under liquid nitrogen atmosphere. Then the scanning was operated by a $\mathrm{Si}_{3} \mathrm{~N}_{4}$ cantilever (Bruker SNL-10, radius of curvature $=2 \mathrm{~nm}$, nominal spring constant $=0.35 \mathrm{~N} \mathrm{~m}^{-1}$ ) at $1.0 \mathrm{nN}$ peak tapping

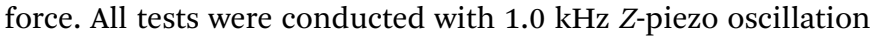
frequency and $150 \mathrm{~nm}$ peak force amplitude under room temperature.

\section{Measurements of contact angle and surface energy}

The surface energy of NR and VMQ was determined according to Owens-Wendt-Rabel-Kaelble (OWRK) method ${ }^{17}$ via measuring contact angle of water (polar liquid) and diiodomethane (non-polar liquid) via video optical contact angle tester (Dataphysics Co., Ltd, America).

Dynamic fatigue crack growth testing and dynamic mechanical thermal analysis (DMTA)

Dynamic fatigue crack growth test was conducted on the DMA + 1000 tester (Metravib Co., Ltd, France) using pure shear (PS) specimen (40 $\mathrm{mm}$ long, $15 \mathrm{~mm}$ high and $2 \mathrm{~mm}$ thick, with double edge pre-notch of $2 \mathrm{~mm}$ by razor blade) as shown in Fig. 2(a). According to eqn (7), $G$ for PS specimen only depends on strain energy density $(W)$, marked by dashed lines as shown in Fig. 2(b) and initial specimen height $\left(h_{0}\right)$, so its $\mathrm{d} c / \mathrm{d} N$ would not be affected by the crack length. ${ }^{\mathbf{1 8 - 2 0}}$

$$
G_{\mathrm{PS}}=W h_{0}
$$

First, a 2000 stretch-retract cycles were applied to the specimen with frequency of $20 \mathrm{~Hz}$ under room temperature to eliminate the Mullins effect in rubber. ${ }^{21}$ Then, a dynamic strain, corresponding to constant $G$ input of $1000 \mathrm{~J} \mathrm{~m}^{-2}$, was conducted for the fatigue crack propagation. ${ }^{22}$ Through locating coordinates of the crack tip by microscope assembled front (Fig. 2(c)), crack growth rate $\mathrm{d} c / \mathrm{d} N$ can be characterized. ${ }^{23}$ Meanwhile, the viscoelastic parameters, including storage modulus $E^{\prime}$, loss factor $\tan \delta$ and loss compliance modulus $J^{\prime \prime}$, were recorded as function of fatigue cycles in the real-time of crack propagation.

Besides, temperature dependence of these three viscoelastic parameters in NR/VMQ vulcanizates were also tested by dynamic mechanical thermal analyzer DMTA (VA-3000, 01dBMetravib Co., Ltd., France). The measurement was conducted in tension mode with temperature range of -80 to $80{ }^{\circ} \mathrm{C}$ and heating rate of $3{ }^{\circ} \mathrm{C} \mathrm{min}^{-1}$, strain of $0.1 \%$ and frequency of $10 \mathrm{~Hz}$.

\section{Results and discussion}

\section{Vulcanization characteristic}

According to torque curves of NR/VMQ compounds during vulcanization process in Fig. 3, it is figured out that except for $80 / 20$ blend, with the increase of VMQ content, the maximum torque values increase, indicating higher cross-linking density. This is attributed to the stronger reactivity between VMQ and curing agent DBPMH in the peroxide vulcanization system, for the methyl and vinyl groups are easier to be attacked by the peroxyl radicals than double bonds and methylene groups in $\mathrm{NR}^{24,25}$ (a)

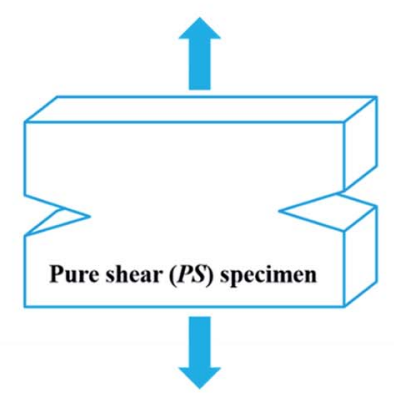

(b)

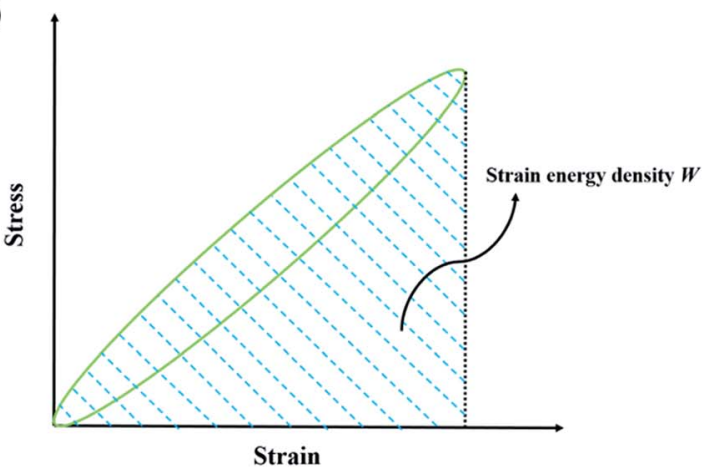

(c)

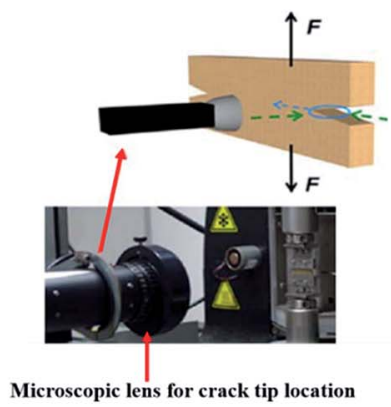

Fig. 2 (a) Geometric representation of pure shear (PS) specimen (b) determining strain energy density $W$ by the stretch-retract curve (c) measure the crack propagation rate $\mathrm{dc} / \mathrm{d} N$ by locating coordinates of the crack tip. 


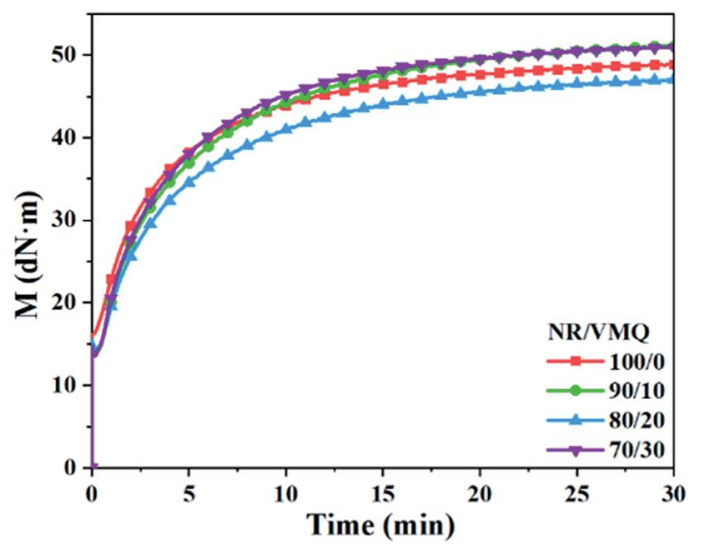

Fig. 3 Torque-time dependency of NR/VMQ compounds during vulcanization.

\section{Filler network and dispersion morphology}

The RPA storage modulus $G^{\prime}$-strain sweeping curves of NR/VMQ vulcanizates are shown in Fig. 4(a). The high $G^{\prime}$ level at lower strains and its rapid decline at higher strains is called Payne effect, ${ }^{26-28}$ which is mainly caused by the existence of filler network under lower strains and its progressive collapse and destruction under higher strains. ${ }^{29-31}$ As can be seen, with more addition of VMQ, $G^{\prime}$ of NR/VMQ increases, which indicates stronger structure of filler network.

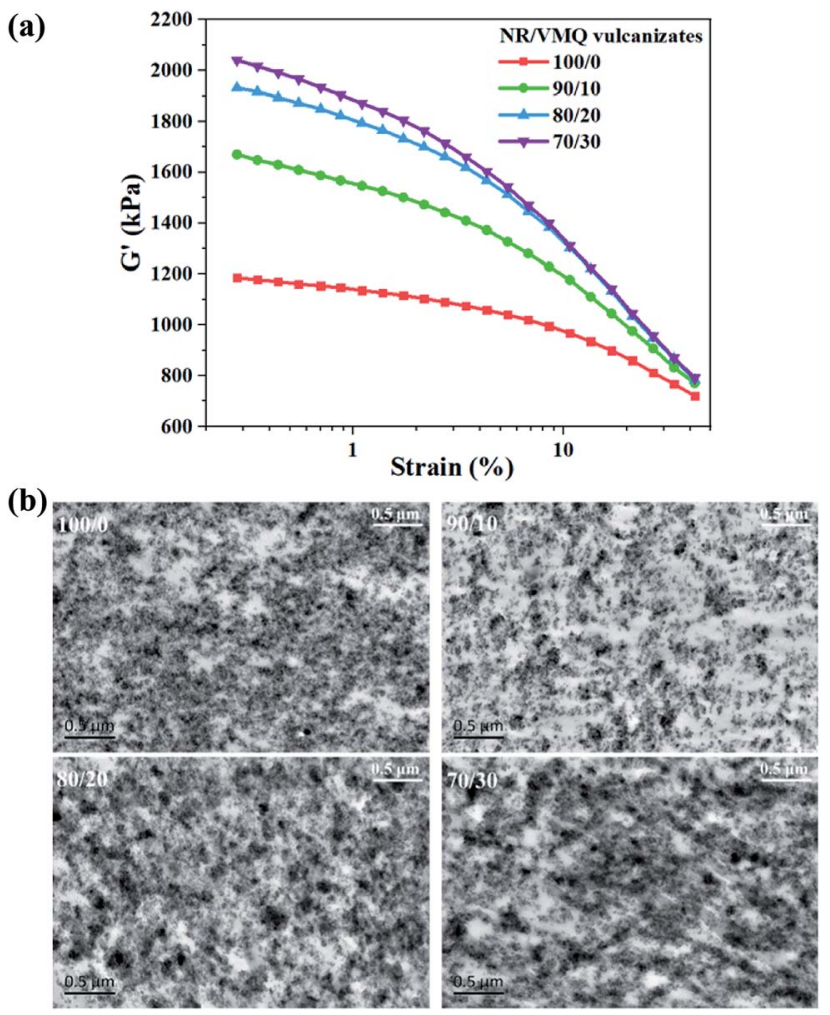

Fig. 4 (a) Strain dependency of storage modulus $G^{\prime}$ of NR/VMQ vulcanizates by RPA (b) photographs of silica dispersion morphology by TEM.
For figuring out the silica dispersion morphology in NR/ VMQ, TEM photographs were taken as shown in Fig. 4(b). With higher VMQ fractions in NR/VMQ, more inhomogeneous dispersion and bigger silica aggregates could be seen, especially for 70/30 blend, which could be correlated with its highest $G^{\prime}$ level.

\section{Phase morphology of NR/VMQ silica masterbatch}

In order to investigate the cause of the uneven filler dispersion in NR/VMQ, phase morphology of NR/VMQ silica masterbatch blends via TEM and AFM are further characterized. Firstly, in $80 / 20$ and 70/30 blends, the pre-mixed silica particles in VMQ masterbatch, marked with red circles in Fig. 5(a), have migrated into NR phase after blending, which proves the different affinity between silica and NR or VMQ phase. This is consistent with the higher silica agglomeration degree in NR/VMQ with higher VMQ content in Fig. 4(a) and (b) mentioned above.

Moreover, the darker area marked by red arrows in Fig. 5(a) and (b) refers to VMQ phase, and the brighter area refers to NR matrix. With increasing VMQ content, the domain size of VMQ phase becomes larger, and exhibits irregular shape and inhomogeneous distribution in NR matrix. As for 70/30 blend, the largest VMQ domains can be seen among the three. The poor compatibility between NR and VMQ could be attributed to their large surface characteristic difference, for the surface energy of pure NR we measured is $25.2 \mathrm{mN} \mathrm{m}^{-1}$, and $17.6 \mathrm{mN} \mathrm{m}^{-1}$ for pure VMQ.

\section{Stress-strain behaviour}

Fig. 6(a) shows the stress-strain curves of NR/VMQ composites including enlarged details at strain range of $0-50 \%$, it can be (a)
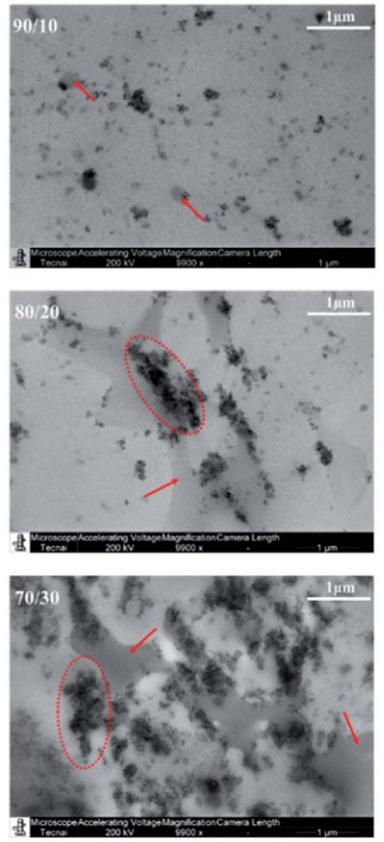

(b)

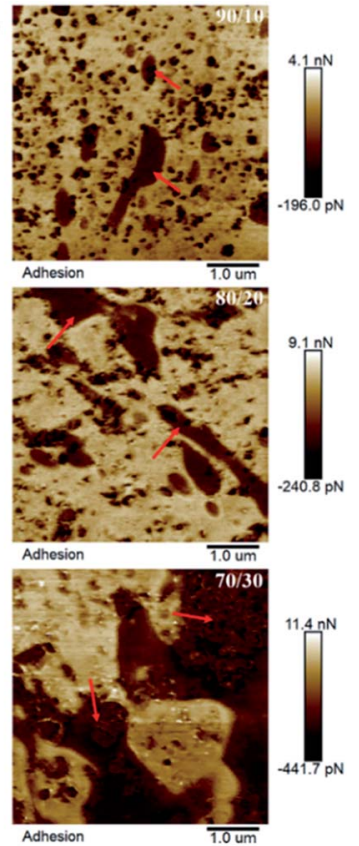

Fig. 5 Photographs of phase morphology of NR/VMQ silica master batch blends by (a) TEM and (b) AFM. 

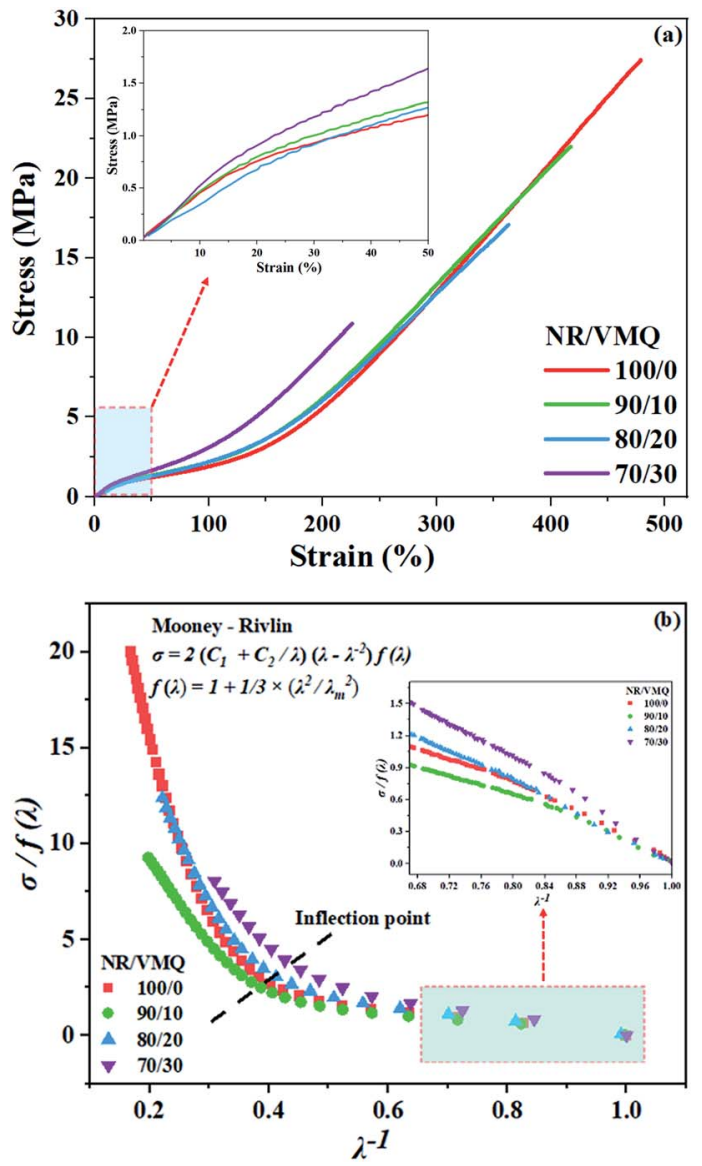

Fig. 6 (a) Stress-strain curves of NR/VMQ composites (b) correspond modified Mooney-Rivlin curves.

seen that although the addition of VMQ decreases ultimate tensile strength of $\mathrm{NR} / \mathrm{VMQ}$, it increases modulus at strains below $50 \%$, which exhibits more evident in $70 / 30$ blend.

As for rubber with strain-induced crystallization (SIC) characteristic, with the increase of strain, the sharp rise of stress is mainly contributed by SIC and the finite extensibility of molecular chains. Furukawa et $a l^{32}$ introduced correction parameter $f(\lambda)$ into Mooney-Rivlin model to exclude effects of

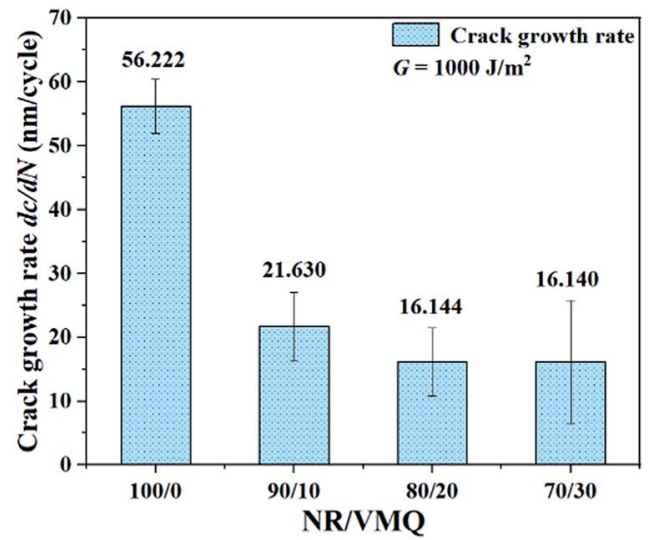

Fig. 7 Dynamic fatigue crack growth rate $d c / d N$ of $N R / V M Q$ composites. the latter, and the inflection point of $\left[\sigma / f(\lambda)-\lambda^{-1}\right]$ plot could represent the extension ratio $\lambda$ when SIC happens. ${ }^{7,33,34}$ So according to the Mooney-Rivlin curves in Fig. 6(b), with increasing VMQ content, the inflection point emerges at lower strain, especially for $70 / 30$ blend, which indicates easier occurrence of SIC. In addition, as for $0.67<\lambda^{-1}<1$, that is, below $50 \%$ strains, $70 / 30$ blend also exhibits the highest $[\sigma / f(\lambda)]$ value among the four composites, which is consistent with the result of the highest modulus in Fig. 6(a).

\section{The relationship between dynamic crack propagation behaviour and viscoelasticity of NR/VMQ composites}

Average values and standard deviations of dynamic fatigue crack growth rate $\mathrm{d} c / \mathrm{d} N$ at constant $G$ input of $1000 \mathrm{~J} \mathrm{~m}^{-2}$ are
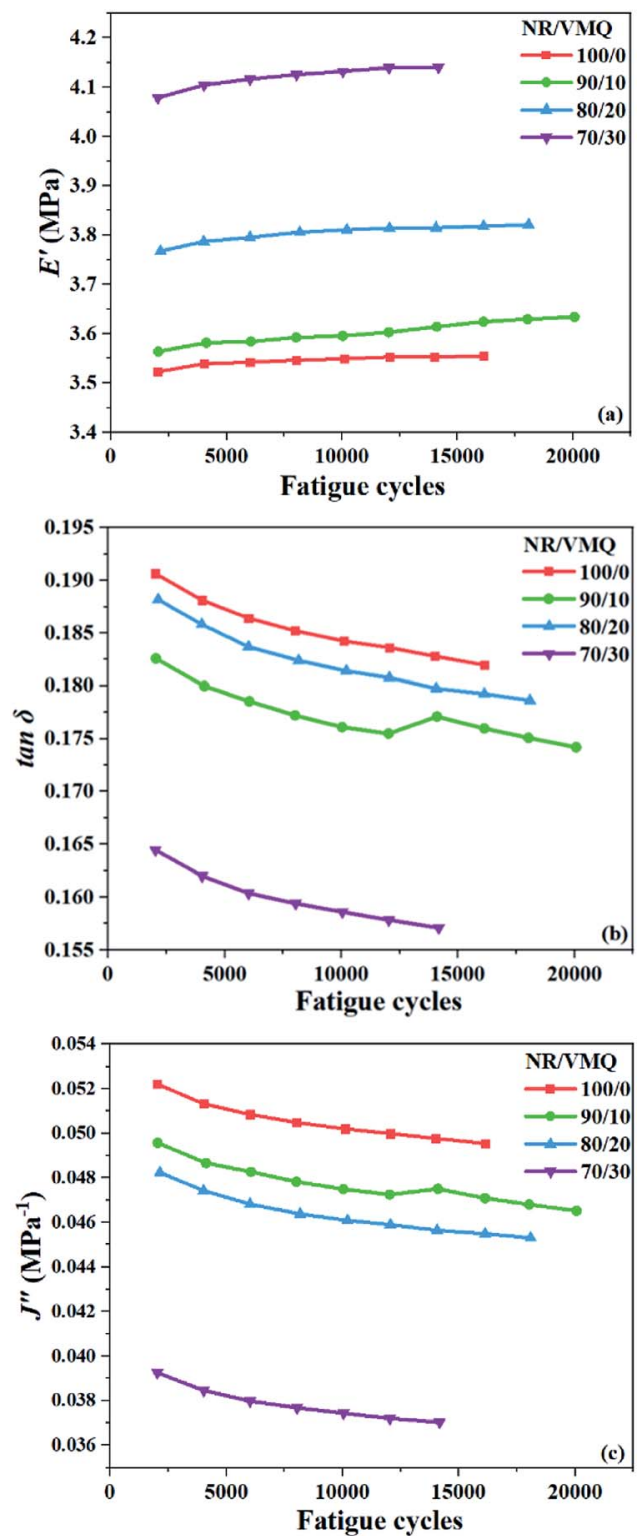

Fig. 8 Viscoelastic parameters of NR/VMQ composites measured as function of fatigue cycles in the real-time of crack propagation: (a) storage modulus $E^{\prime}$, (b) loss factor $\tan \delta$ and (c) loss compliance modulus $\mathrm{J}^{\prime \prime}$. 


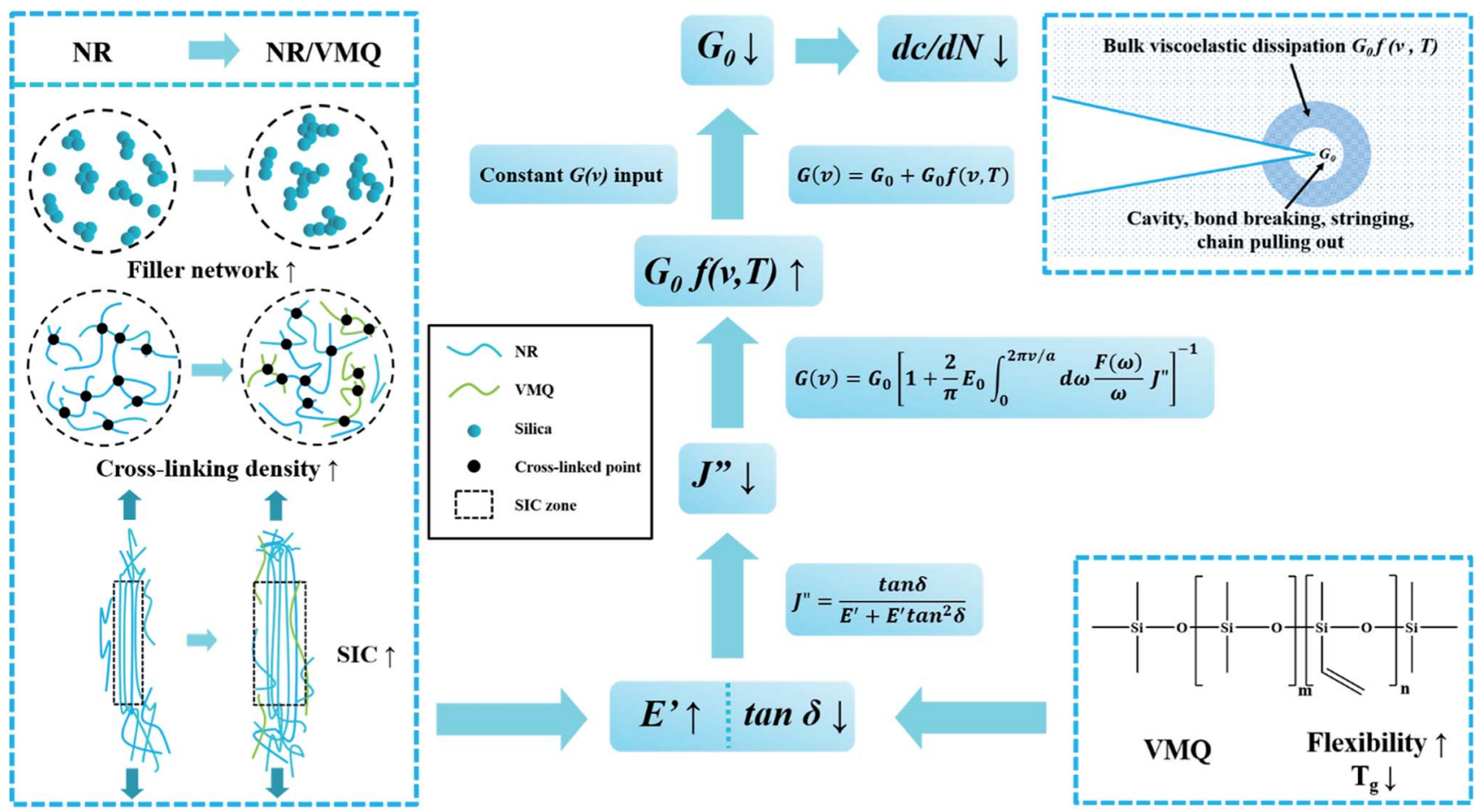

Fig. 9 Mechanism sketch of the improved crack propagation resistance of NR/VMQ with addition of VMQ.

shown in Fig. 7. It is pointed out that the addition of VMQ could improve the crack propagation resistance of NR/VMQ, for 80/20 and $70 / 30$ blends exhibit the lowest $\mathrm{d} c / \mathrm{d} N$, and pure NR shows the highest $\mathrm{d} c / \mathrm{d} N$ among the four composites.

According to Persson and Brener's theory introduced above, ${ }^{4,5}$ storage modulus $E^{\prime}$, loss factor tan $\delta$ and loss compliance factor $J^{\prime \prime}$ were selected for recording as function of fatigue cycles in the real-time of crack propagation as shown in Fig. 8(a)-(c), respectively, which in order to build up connections between crack propagation properties and viscoelasticity of NR/VMQ composites.

With addition of VMQ, $E^{\prime}$ of NR/VMQ increases compared with that of NR as shown in Fig. 8(a), especially for 70/30 blend. As for $\tan \delta$, it appears decline in NR/VMQ with higher VMQ fraction in Fig. 8(b). Evident decrease of $J^{\prime \prime}$ with more addition of VMQ has been found in Fig. 8(c), this is consistent with eqn
(5), for the combined effects of the increased $E^{\prime}$ and decreased $\tan \delta$ would finally cause the decline of $J^{\prime \prime}$.

Besides, for further evidence, temperature dependency of $E^{\prime}, \tan \delta$ and $J^{\prime \prime}$ were also characterized by DMTA as shown in Fig. S1(a)-(c), $\dagger$ respectively, including enlarged details at 20$70{ }^{\circ} \mathrm{C}$. Similar results have been acquired as mentioned above in Fig. 8(a)-(c), with increasing VMQ fraction, $E^{\prime}$ increases, $\tan \delta$ and $J^{\prime \prime}$ decrease in the three NR/VMQ composites.

On the basis of the above results, we proposed the mechanism sketch of improved crack propagation resistance of NR/ VMQ in Fig. 9. On the one hand, incorporation of VMQ into NR caused stronger silica filler network, higher cross-linking density, and easier occurrence of SIC compared with NR, and correspondingly NR/VMQ exhibited higher stress level at smaller strains, that is, the increased $E^{\prime} \cdot{ }^{35}$ On the other hand,
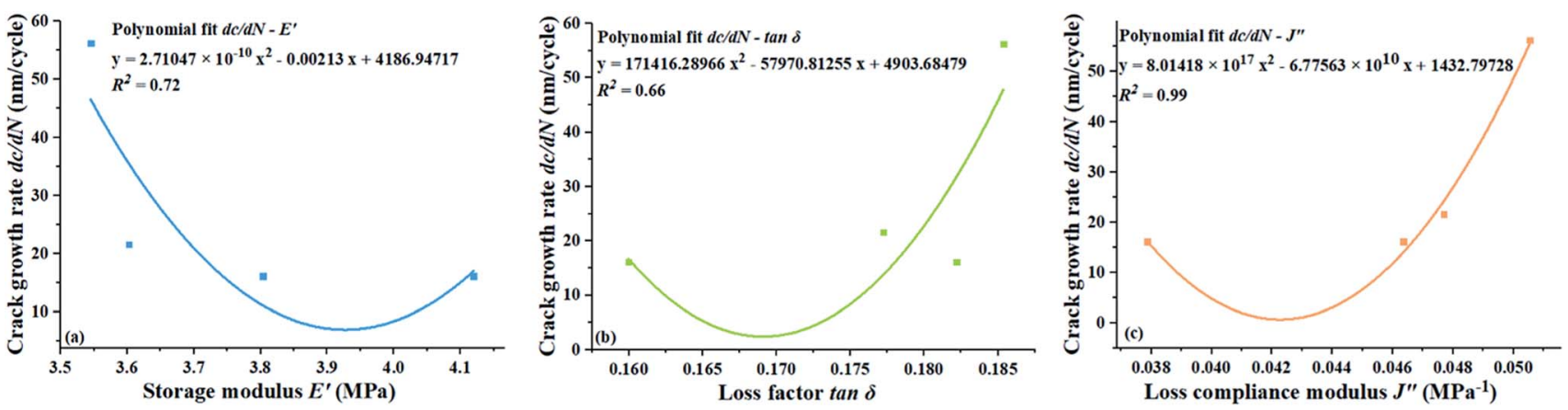

Fig. 10 Polynomial fit between crack growth rate $\mathrm{dc} / \mathrm{d} N$ and viscoelastic parameters of NR/VMQ: (a) $\mathrm{d} c / \mathrm{d} N-E^{\prime}$, (b) $\mathrm{dc} / \mathrm{d} N-\tan \delta$ and (c) dc/dN$\mathrm{J}^{\prime \prime}$. 
due to the flexible chain structure and quite low glasstransition temperature of VMQ, NR/VMQ showed lower $\tan \delta$ relative to NR. The synergistic effect of the increased $E^{\prime}$ and decreased $\tan \delta$ would lead to the decrease of $J^{\prime \prime}$. Lower $J^{\prime \prime}$ resulted in higher $G_{0} f(v, T)$, which demonstrated more energy dissipation in the bulk linear viscoelastic region. ${ }^{4}$ As for constant $G(v)$ input in our study, higher $G_{0} f(v, T)$ means lower $G_{0}$, and so the energy used as crack propagation would decrease. ${ }^{5,36}$ As a result, the crack propagation resistance of NR/VMQ was improved.

Further, polynomial fitting of $\mathrm{d} c / \mathrm{d} N-E^{\prime}, \mathrm{d} c / \mathrm{d} N-\tan \delta$ and $\mathrm{d} c /$ $\mathrm{d} N-J^{\prime \prime}$ have been done for revealing the underlined linkages between them, as shown in Fig. 10(a)-(c), respectively, for the viscoelastic parameters were chosen as the average values of different fatigue cycles in Fig. 8. It is worth noting that $\mathrm{d} c / \mathrm{d} N-J^{\prime \prime}$ exhibits the best relevance $\left(R^{2}=0.99\right)$ among the three fitting curves, which proves the combined effects of $E^{\prime}$ and $\tan \delta$ on $J^{\prime \prime}$ again. Therefore, loss compliance modulus $J^{\prime \prime}$ is a reliable viscoelastic parameter to correlate with the crack propagation behaviour of NR/VMQ composites.

\section{Conclusions}

In this study, dynamic fatigue crack propagation properties of NR/VMQ composites at constant $G$ input of $1000 \mathrm{~J} \mathrm{~m}^{-2}$ are emphatically discussed. Results showed that more addition of VMQ could improve crack propagation resistance of NR/VMQ. The mechanism of this phenomenon has been put forward by characterizing the viscoelastic parameters in the real-time of fatigue process, and good correlation has been established between loss compliance modulus $J^{\prime \prime}$ and crack growth rate $\mathrm{d} c /$ $\mathrm{d} N$. The synergistic effect of the increased $E^{\prime}$ and decreased $\tan \delta$ cause the decline of $J^{\prime \prime}$. Then the corresponding bulk energy dissipation $G_{0} f(v, T)$ in the linear viscoelastic region in front of the crack tip has been strengthened, as for constant $G(v)$ input, energy used as crack propagation $G_{0}$ would decrease, which contributed to the declined crack propagation rate. Therefore, $J^{\prime \prime}$ is a reliable viscoelastic parameter to correlate with the crack growth behaviour of NR/VMQ composites.

\section{Conflicts of interest}

There are no conflicts to declare.

\section{Acknowledgements}

The authors are grateful for the financial supports from the National Key Research and Development Program of China (No. 2017YFB0307002).

\section{References}

1 R. S. Rivlin and A. G. Thomas, J. Polym. Sci., 1953, 10, 291318.

2 G. J. Lake, Rubber Chem. Technol., 1995, 68, 435-460.
3 M. E. Yaagoubi, D. Juhre, J. Meier, N. Kröger, T. Alshuth and U. Giese, Int. J. Fatigue, 2018, 112, 341-354.

4 B. N. J. Persson and E. A. Brener, Phys. Rev. E, 2005, 71, 036123.

5 B. N. J. Persson, O. Albohr, G. Heinrich and H. Ueba, J. Phys.: Condens. Matter, 2005, 17, 1071-1142.

6 S. Rooj, A. Das, I. A. Morozov, K. W. Stöckelhuber, R. Stocek and G. Heinrich, Compos. Sci. Technol., 2013, 76, 61-68.

7 Y. J. Nie, B. Y. Wang, G. S. Huang, L. L. Qu, P. Zhang, G. S. Weng and J. R. Wu, J. Appl. Polym. Sci., 2010, 117, 3441-3447.

8 M. J. Li, Y. Li, J. Zhang and S. Feng, Polym. Eng. Sci., 2014, 54, 355-363.

9 T. T. N. Dang, J. K. Kim and K. J. Kim, J. Vinyl Addit. Technol., 2010, 16, 254-260.

10 H. J. Kim and G. R. Hamed, Rubber Chem. Technol., 2000, 73, 743-752.

11 K. Sahakaro, N. Naskar, R. N. Datta and J. W. M. Noordermeer, J. Appl. Polym. Sci., 2007, 103, 25382546.

12 W. H. Waddell, Rubber Chem. Technol., 1998, 71, 590-618.

13 J. R. Beatty, Rubber Chem. Technol., 1964, 37, 1341-1364.

14 Y. Morishita, K. Tsunoda and K. Urayama, Polymer, 2019, 179, 121651.

15 Y. Morishita, K. Tsunoda and K. Urayama, Phys. Rev. E, 2016, 93, 043001.

16 Z. Sun, Q. Huang, Y. Z. Wang, L. Q. Zhang and Y. P. Wu, Ind. Eng. Chem. Res., 2017, 56, 1471-1477.

17 D. K. Owens and R. C. Wendt, J. Appl. Polym. Sci., 1969, 13, 1741-1747.

18 B. Dong, C. Liu and Y. P. Wu, Polym. Test., 2014, 38, 40-45. 19 G. Andreini, P. Straffi, S. Cotugno, G. Gallone and G. Polacco, Rubber Chem. Technol., 2013, 86, 132-145.

20 R. Stoček, G. Heinrich, M. Gehde and R. Kipscholl, Fracture Mechanics \& Statistical Mech, LNACM, vol. 70, pp. 269-301.

21 Y. X. Ding, X. J. Cao, G. S. Weng, Q. Y. Yin, L. T. Wang and Z. R. Chen, J. Appl. Polym. Sci., 2017, 134, 44527.

22 A. J. Chang, G. S. Weng, K. Fu, Y. X. Ding and D. R. Gong, J. Appl. Polym. Sci., 2016, 133, 42972.

23 H. Yao, G. S. Weng, Y. P. Liu, K. Fu, A. J. Chang and Z. R. Chen, J. Appl. Polym. Sci., 2015, 132, 41980.

24 J. Kruželák, R. Sýkora and I. Hudec, Rubber Chem. Technol., 2017, 90, 60-88.

25 R. Rajan, S. Varghese and K. E. George, Rubber Chem. Technol., 2016, 86, 488-502.

26 R. Q. Yang, Y. H. Song and Q. Zheng, Polymer, 2017, 116, 304-313.

27 Z. Sun, Q. Huang, L. Q. Zhang, Y. Z. Wang and Y. P. Wu, RSC Adv., 2017, 7, 38915-38922.

28 L. L. Qu, L. J. Wang, X. M. Xie, G. Z. Yu and S. H. Bu, RSC $A d v .$, 2014, 4, 64354-64363.

29 H. M. Zhou, L. X. Song, A. Lu, T. Jiang, F. M. Yu and X. C. Wang, RSC Adv., 2016, 6, 15155-15166.

30 A. Das, K. W. Stöckelhuber, R. Jurk, M. Saphiannikova, J. Fritzsche, H. Lorenz, M. Klüppel and G. Heinrich, Polymer, 2008, 49, 5276-5283. 
31 S. K. Srivastava and Y. K. Mishra, Nanomaterials, 2018, 8, 945.

32 J. Furukawa, Y. Onouchi, S. Inagaki and H. Okamoto, Polym. Bull., 1981, 6, 381-387.

33 B. Dong, C. Liu, Y. L. Lu and Y. P. Wu, J. Appl. Polym. Sci., 2015, 132, 42075.
34 B. Dong, C. Liu, L. Q. Zhang and Y. P. Wu, RSC Adv., 2015, 5, 17140-17148.

35 S. B. Zhang, L. Zheng, D. H. Liu, Z. C. Xu, L. Q. Zhang, L. Liu and S. P. Wen, RSC Adv., 2017, 7, 40813-40818.

36 P. Ghosh, R. Stoček, M. Gehde, R. Mukhopadhyay and R. Krishnakumar, Int. J. Fract., 2014, 188, 9-21. 